\title{
New inorganic nanotube polymer nanocomposites: improved thermal, mechanical and tribological properties in isotactic polypropylene incorporating INT-MoS
}

\author{
Mohammed Naffakh, ${ }^{* a b}$ Ana M. Díez-Pascual, ${ }^{b}$ Maja Remškar ${ }^{c d}$ and Carlos Marco ${ }^{b}$ \\ Received 28th May 2012, Accepted 26th June 2012 \\ DOI: 10.1039/c2jm33422d \\ Environmentally friendly molybdenum disulfide (INT- $\left.\mathrm{MoS}_{2}\right)$ inorganic nanotubes were introduced \\ into an isotactic polypropylene (iPP) polymer matrix to generate novel nanocomposite materials \\ through an advantageous melt-processing route. The effects of INT-MoS $\mathrm{S}_{2}$ content on the thermal, \\ mechanical and tribological properties were investigated. The incorporation of INT-MoS 2 generates \\ notable performance enhancements through reinforcement effects, highly efficient nucleation activity \\ and excellent lubricating ability in comparison with other nanoparticle fillers such as nanoclays, carbon \\ nanotubes, silicon nitrides and halloysite nanotubes. It was shown that these INT-MoS \\ nanocomposites can provide an effective balance between performance, cost effectiveness and \\ processability, and should be of some interest in the area of multifunctional polymer nanocomposite \\ materials.
}

\section{Introduction}

Polymer-based nanocomposites containing strong, durable and multifunctional nanoparticles such as silicates, fullerenes, carbon nanotubes, graphenes, etc. have been considered as promising advanced materials because of the improved properties that can be achieved compared to conventional polymer composites when the nanoparticles are homogeneously dispersed in the polymeric matrix. ${ }^{1-6}$ To reach high performance and possible commercial success for the nanocomposites, even at a low nanoparticle content, the key factors to be considered include the availability of cost-effective nanoparticles with the proper inherent properties and optimised nanoparticle dispersion, interface chemistry and nanoscale morphology. Accordingly, much research on polymer-based nanocomposites has been performed, initially with interesting observations involving exfoliated clays and more recent studies with carbon nanotubes, carbon nanofibers, exfoliated graphite (graphene), nanocrystalline metals and a host of other nanoscale inorganic filler or fiber modifications. ${ }^{1-6}$

Inorganic nanotubes (INT) and inorganic fullerene-like (IF) nanoparticles represent an emerging field with a great potential

${ }^{a}$ Universidad Politécnica de Madrid, Departamento de Ingeniería y Ciencia de Los Materiales, Escuela Técnica Superior de Ingenieros Industriales, José Gutiérrez Abascal 2, 28006 Madrid, Spain. E-mail: mohammed. naffakh@upm.es; Fax: +34 913363 007; Tel: +34913363164

${ }^{b}$ Instituto de Ciencia y Tecnología de Polímeros, ICTP-CSIC, c/Juan de la Cierva, 3, 28006, Madrid, Spain

'Solid State Physics Department, Jozef Stefan Institute, Jamona 39, SI1000 Ljubljana, Slovenia

${ }^{d}$ Centre of Excellence PoliMat, Tehnoloski Park 24, SI-1000 Ljubljana, Slovenia for further development. The first syntheses of $\mathrm{WS}_{2}$ and $\mathrm{MoS}_{2}$ nanotubes and fullerene-like nanoparticles were reported by Tenne in 1992 and 1993, respectively. ${ }^{7,8}$ Since then the number of reports on the successful growth of nanotubes from inorganic compounds has increased rapidly, emphasizing the importance of this field for nanotechnology, and potential applications in catalysis, rechargeable batteries, drug delivery, solar cells and electronics have been described., ${ }^{9,10}$ The physical properties of $\mathrm{WS}_{2}$ and $\mathrm{MoS}_{2}$ nanostructures (IF and INT) have been studied in detail, both experimentally and by theoretical modelling. These properties are interesting not only academically but also because these kinds of nanostructures show substantial potential for becoming part of the ultrahigh-strength nanocomposite technology. In particular, the incorporation of environmentally friendly inorganic fullerene-like tungsten disulfide (IF-WS $\left.{ }_{2}\right)$ nanoparticles has been shown to be efficient for improving the thermal, mechanical and tribological properties in a number of thermoplastic polymers, including isotactic polypropylene (iPP), ${ }^{11}$ polyphenylene sulfide (PPS), ${ }^{12}$ poly(ether ether ketone) (PEEK), ${ }^{13}$ and nylon-6, ${ }^{14}$ which were processed via traditional melt-processing techniques without the need for modifiers, surfactants or dispersing agents. More specifically, since the beginning of 2011 we have successfully developed a new family of nanocomposites which integrated molybdenum disulfide nanotubes $\left(\mathrm{MoS}_{2}\right)$ into an isotactic polypropylene matrix, one of the most widely investigated polymers in the preparation and application of nanocomposites, employing a simple and costeffective melt-processing route. ${ }^{15}$ This strategy yields finer dispersion, with INT- $\mathrm{MoS}_{2}$ almost fully debundled into individual tubes or small clusters, which are randomly oriented in the 
iPP matrix. The minimum diameter of INT-MoS 2 was about 80 $\mathrm{nm}$ and they were $200 \mu \mathrm{m}$ in length. ${ }^{15}$ Successful dispersions of INT- $\mathrm{MoS}_{2}$ have been demonstrated by a remarkable improvement in the thermal stability, crystallization processes and dynamic-mechanical properties of iPP. ${ }^{15-17}$ Another kind of highly studied system is polymer-based nanocomposites containing INT-WS $\mathrm{W}_{2}$ inorganic nanotubes that are now commercially produced in bulk quantities (http://www.apnano.com). ${ }^{18}$ Taking advantage of this achievement, high-performance materials with different morphologies, such as epoxy/INT-WS $\mathrm{W}_{2}$ and PMMA/INT-WS 2 nanofibers, have been successfully developed. ${ }^{19,20}$ In particular, the enhancement reported in stiffness and toughness of PMMA fiber meshes with INT-WS 2 predicts their potential usage as high energy transparent materials with adjustable polarizability and dielectric constants. ${ }^{20}$

The present work is focused on the analysis of the influence of INT-MoS 2 loading on the structure-property-performance relationship of iPP/INT- $\mathrm{MoS}_{2}$ nanocomposites. In particular, the processability and dispersion of INT-MoS 2 were considered when evaluating thermal, tribological and mechanical response and performance of these new formulations in comparison with those previously reported in other iPP nanocomposite systems.

\section{Experimental section}

\subsection{Materials and methods}

The polypropylene (PP) used as the matrix was a commercial isotactic homopolymer provided by REPSOL, with a polydispersity of 4.77 , an isotacticity of $95 \%$ and a viscosity average molecular weight of $179000 \mathrm{~g} \mathrm{~mol}^{-1}$. $\mathrm{MoS}_{2}$ nanotubes provided by NANOTUL (Slovenia) have been synthesized from $\mathrm{Mo}_{6} \mathrm{~S}_{2} \mathrm{I}_{8}$ nanowires, which have been sulphurized at $1023 \mathrm{~K}$ in flowing $\mathrm{Ar}$ gas containing $1 \%$ of $\mathrm{H}_{2} \mathrm{~S}$ and $1 \%$ of $\mathrm{H}_{2}{ }^{21}$ X-ray fluorescence analysis revealed $\mathrm{MoS}_{2}(99.9 \%)$ with some traces of iodine (200 ppm). The kinetics of the sulphurization process, especially temperature and the reaction rate, determine the morphology of the final product. Nanotubes grow in a very wide range of sizes depending on the local conditions in the growing tube. In diameter they size between a few tens and a few hundred $\mathrm{nm}$, while in lengths from a few micrometers up to several millimetres. A slow release of iodine leads to formation of nanotubes composed of several coaxial cylinders showing a high concentration of structural defects. ${ }^{22}$ Difference in the mass density between $\mathrm{Mo}_{6} \mathrm{~S}_{2} \mathrm{I}_{8}$ and $\mathrm{MoS}_{2}$ compounds leads to a creation of an empty space inside the $\mathrm{MoS}_{2}$ nanotubes (Fig. 1a). ${ }^{15}$ The surface structure mode shows corrugations along the nanotubes axis (Fig. 1b), which are explained by the lamellar structure of the starting material. ${ }^{23}$ Several concentrations of INT-MoS $2(0.1,0.5$ and $1 \mathrm{wt} \%$ ) were introduced in the iPP matrix by melt-mixing using a micro-extruder (Thermo-Haake Minilab system) operated at $210{ }^{\circ} \mathrm{C}$ with a rotor speed of $150 \mathrm{rpm}$ for $15 \mathrm{~min}$.

\subsection{Characterization techniques}

The surface structure of $\mathrm{MoS}_{2}$ nanotubes was studied with a commercial scanning tunneling microscope-STM (VT-AFM, Omicron) under ultrahigh vacuum conditions at $10^{-10} \mathrm{mbar}$ and at room temperature. A chemically etched tungsten tip was used as the STM probe. Tensile and flexural properties were measured
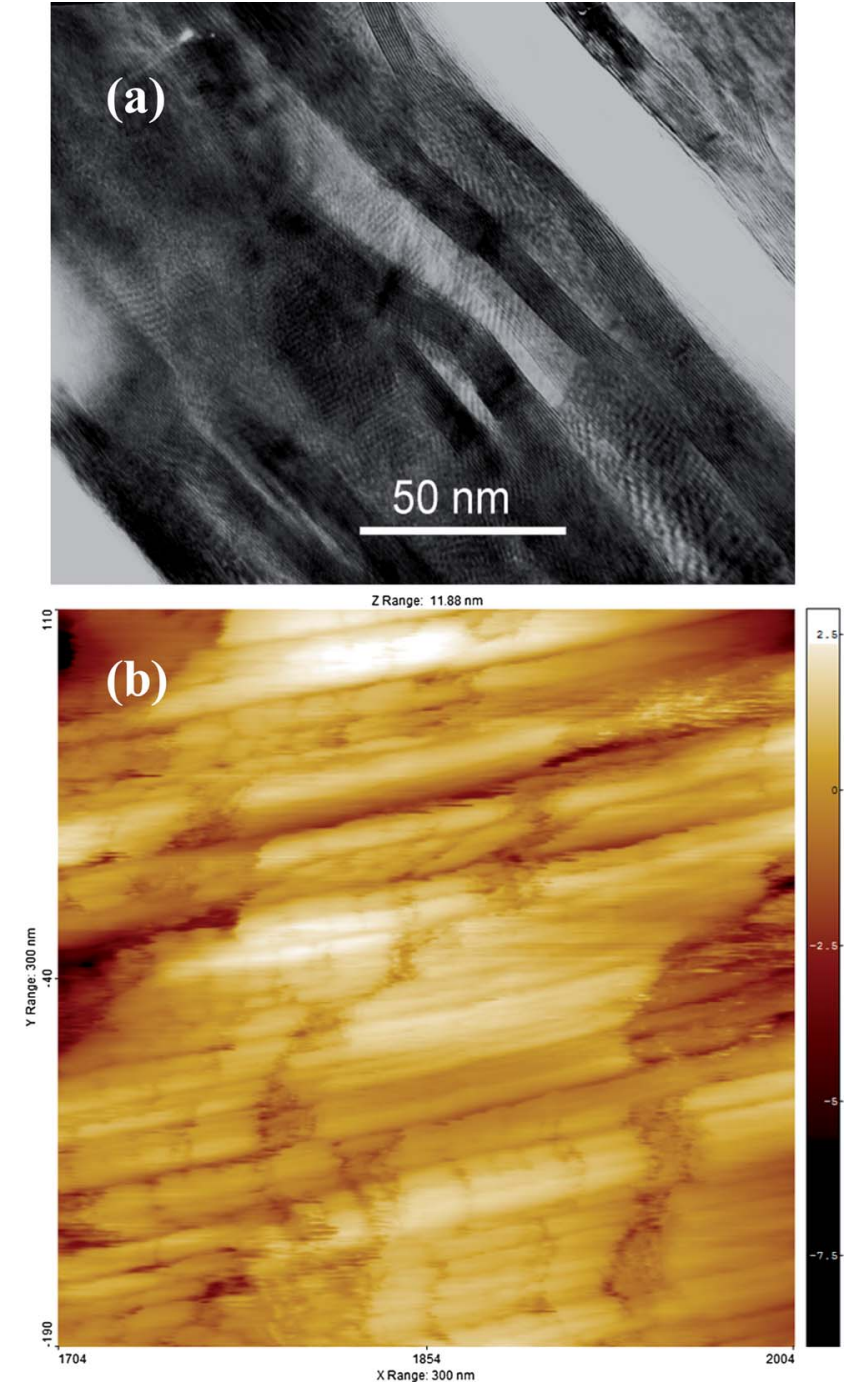

Fig. 1 (a) HRTEM and (b) STM images of the surface structure of $\mathrm{MoS}_{2}$ nanotubes $\left(U_{\mathrm{T}}=0.5 \mathrm{~V} ; I_{\mathrm{T}}=0.5 \mathrm{nA}\right)$.

with an INSTRON 4204 mechanical tester at room temperature and $50 \pm 5 \%$ relative humidity, using a crosshead speed of $1 \mathrm{~mm}$ $\min ^{-1}$ and a load cell of $1 \mathrm{kN}$. Tensile specimens (Type V) and rectangular flexural bars were employed according to UNE-EN ISO 527-1 and 178 standards, respectively. All the samples were conditioned for $24 \mathrm{~h}$ before the measurements. The data reported are the average of the results for 5 specimens. Charpy notched impact strength measurements were carried out using a CEAST Fractovis dart impact tester. A hammer mass of $1.096 \mathrm{~kg}$ impacted at a constant velocity of $3.60 \mathrm{~ms}^{-1}$ and an energy of $7.10 \mathrm{~J}$ on notched specimen bars of length $=33 \mathrm{~mm}$, width $=$ $10 \mathrm{~mm}$, and thickness $=3 \mathrm{~mm}$, with a V-shape notch of tip radius $=0.25 \mathrm{~mm}$ and depth $=2 \mathrm{~mm}$, as described in the UNE-EN ISO 179 standard. Measurements were performed at $23 \pm 2{ }^{\circ} \mathrm{C}$ and $50 \pm 5 \%$ relative humidity. The data presented correspond to the average value of at least 6 test specimens. Tribological properties were measured with a Microtest MT 40098 pin-on-disk testing machine, using a $6 \mathrm{~mm}$ diameter $100 \mathrm{Cr} 6$ steel ball-like pattern slide. Tests were carried out under a constant loading of $5 \mathrm{~N}$ at a rotation speed of $375 \mathrm{rpm}$. The 
equipment was placed in an isolated box to control the atmospheric conditions, and the experiments were performed in air at a temperature of $24 \pm 2{ }^{\circ} \mathrm{C}$ and a relative humidity of $22 \pm 2 \%$. The wear experienced by the flat substrate was determined through the measurement of the wear-track profile by using a profilometer with a resolution of $\sim 10 \mathrm{~nm}$. Each tribological test was repeated three times to report an average value. The surface free energy of the polymeric films was evaluated through contact angle measurements using the sessile drop method. Experiments were carried out at room temperature using a Krüss G10 contact angle measurement system. Two liquids with different polarity were used to measure the static contact angle: water $(\gamma=72.8$ $\left.\mathrm{mN} \mathrm{m}^{-1}\right)$ and diiodomethane $\left(\gamma=50.8 \mathrm{mN} \mathrm{m}^{-1}\right)$. The angles were measured by dropping with a syringe ten drops $(\sim 0.5 \mu \mathrm{l})$ of each liquid on different positions of the solid surface. The image of the drop was captured by a video camera connected to a computer, and the image was analyzed to calculate the contact angle. Subsequently, the surface energy of the sample was determined using the Owens-Wendt-Rabel-Kaelble method. ${ }^{24}$

$$
(1+\cos \theta) \sigma_{1}=2\left(\sigma_{\mathrm{s}}^{\mathrm{d}} \sigma_{1}^{\mathrm{d}}\right)^{1 / 2}+2\left(\sigma_{\mathrm{s}}^{\mathrm{p}} \sigma_{1}^{\mathrm{p}}\right)^{1 / 2}
$$

where $\theta$ is the measured contact angle, $\sigma_{1}$ is the total surface energy of the liquid in contact with the solid, $\sigma_{1}^{\mathrm{d}}$ and $\sigma_{\mathrm{p}}^{\mathrm{p}}$ are the dispersion and polar components of the liquid, respectively; $\sigma_{\mathrm{s}}^{\mathrm{d}}$ and $\sigma_{\mathrm{s}}^{\mathrm{p}}$ are the dispersion and polar components of the solid surface. Taking into account the surface energies of the liquids used for contact angle tests (water: $\sigma^{\mathrm{p}}=51.0 \mathrm{mN} \mathrm{m}^{-1} ; \sigma_{1}^{\mathrm{d}}=$ $21.8 \mathrm{mN} \mathrm{m}^{-1}$; diiodimethane: $\sigma_{1}^{\mathrm{p}}=2.3 \mathrm{mN} \mathrm{m}^{-1} ; \sigma_{1}^{\mathrm{d}}=48.5$ $\mathrm{mN} \mathrm{m}^{-1}$ ), the surface energy of the solid was obtained according to the above equation. The thermal behaviour of iPP/INT- $\mathrm{MoS}_{2}$ nanocomposites was characterized using thermogravimetric analysis (TGA) and differential scanning calorimetry (DSC). A detailed description of the characterization techniques is given in a previous work. ${ }^{15}$

\section{Results and discussion}

\subsection{Crystallization and thermal stability}

Recently iPP nanocomposites consisting nanoparticle fillers have attracted great attention due to their scientific and technological importance. Compared with conventional iPP composites iPP nanocomposites usually exhibit markedly different processability and performance that are significantly affected by the crystallization of the iPP matrix. Incorporating well-dispersed nanoparticles like INT-MoS 2 into iPP can modify the crystallization behavior. ${ }^{15}$ Generally the nanoparticles influence the crystallization process of iPP by acting as heterogeneous nuclei leading to increases in the nucleation and crystallization rates. As a result increased crystallization temperatures and finer spherulites are observed. Table 1 summarizes the findings of several studies on the nucleating efficiency (NE) of nanoreinforcing fillers with different morphologies such as tubular, spherical and laminarlike particles on the crystallization of the PP matrix. It is important to note that the INT-MoS 2 and IF-WS ${ }_{2}$ nanoparticles $^{11}$ are about 5 times heavier than other reported nanofillers (e.g., HNTs, CNTs, nanoclay), hence the ideal comparison should be done in vol\%, taking into account the specific gravity of each nanofiller. However, in this study we have selected the $\mathrm{wt} \%$ parameter to make the comparison easier, since it was employed in all the cited references. The NE values are calculated according to the procedure of Lotz and co-workers ${ }^{25,26}$ using the crystallization peak temperatures $\left(T_{\mathrm{p}}\right)$ of the virgin and best nucleated iPP attainable via self-nucleation $\left(T_{\mathrm{p}}=140{ }^{\circ} \mathrm{C}\right.$ (ref. 27)). In this situation $\mathrm{NE}=0$ for a non-nucleating action and $\mathrm{NE}=100$ for optimum efficiency. For example, to make a simple comparison, the data observed for a fixed concentration of nanofillers, i.e. $1 \mathrm{wt} \%$, clearly indicate that the INT-MoS 2 is an effective nucleating agent for the crystallization of iPP. The value of NE $\sim 30 \%$ obtained for INT- $\mathrm{MoS}_{2}$ is noticeably higher than the value of $24 \%$ recently observed for other inorganic nanotubes (halloysites) that have been reported as promising candidates for the preparation of new structural and functional materials. ${ }^{28}$ Clearly, the NE value for INT- $\mathrm{MoS}_{2}$ far exceeds the values observed for montmorillonite nanoclay ${ }^{29}$ and $\operatorname{rod}-\mathrm{Si}_{3} \mathrm{~N}_{4},{ }^{30}$ and is comparable to that observed for MWCNTs. ${ }^{31}$ However, the nucleation efficiency of INT- $\mathrm{MoS}_{2}$ is significantly lower in comparison to the value of $40 \%$ observed for inorganic fullerenelike $\mathrm{WS}_{2}$ nanoparticles at $1 \mathrm{wt}^{\%}{ }^{1{ }^{11}}$ Differences in NE are generally related to various factors such as the ability to form the critical nucleus, which may be favoured in the presence of IF-WS 2 , and the variation of intrinsic parameters of the nanofillers such as surface energy and roughness and crystalline structure (e.g. in IF-WS $\mathrm{W}_{2}$ the presence of a crystalline diffraction peak in WAXS at $2 \theta=14^{\circ}$, corresponding to $0.614 \mathrm{~nm}$, a spacing similar to that of the 110 peak in iPP appears to favour the epitaxial crystallization of the iPP matrix ${ }^{\mathbf{1 1}}$ ).

Besides the improved crystallization rate of iPP, INT-MoS can also alter its thermal stability, and the influence of INT-MoS $\mathrm{S}_{2}$ on the degradation behavior of PP has been evaluated by TGA. As an example, the characteristic weight loss temperatures for the PP nanocomposites in nitrogen are summarized in Table 1. The data reveal that the concentration of non-modified INT- $\mathrm{MoS}_{2}$ has a dramatic effect on the thermal stability of the iPP nanocomposites. The temperature at $10 \%$ weight loss $\left(T_{10}\right)$ of iPP/INT-MoS $(1 \mathrm{wt} \%)$ is almost $60{ }^{\circ} \mathrm{C}$ higher than that of neat iPP, suggesting that INT-MoS $\mathrm{S}_{2}$ has outstanding properties for improving the thermal stability at a low nanofiller content. As a comparison, approximately the same increment was observed for iPP nanocomposites filled with $10 \mathrm{wt}$ $\%$ of modified HNTs (silane). In the case of iPP/HNTs the thermal stability and flame-retardant effects are believed to result from the hollow tubular structure of HNTs, the barriers for heat and mass transport and the presence of iron in the HNTs. ${ }^{32}$

Similarly, the incorporation of CNTs can also lead to improvement in the thermal stability of iPP, although this is generally limited with pristine MWCNTs ( $1 \mathrm{wt} \%$ ) to increments of around $10{ }^{\circ} \mathrm{C},{ }^{33}$ and the application of more sophisticated incorporation methods such as nanotube functionalization or the use of surfactants or interfacial agents is required. In some cases a further improvement can be observed, for example, the decomposition temperature $\left(T_{10}\right)$ of a PP/MA-g-PP/diamineMWCNTs composite was increased by $50{ }^{\circ} \mathrm{C}$ compared to that of iPP. ${ }^{34}$ The significant increase in thermal stability of PP/MA$g$-PP/diamine-MWCNT composite was attributed to chemical adsorption of MA- $g$-PP on the diamine-MWCNT surfaces as well as physical adsorption. Marosfói et al. ${ }^{35}$ also reported that the thermal stabilization effect of carbon nanotubes could be 
Table 1 Crystallization, nucleation data and thermal stability for iPP nanocomposites using nanoreinforcing fillers with different morphologies (e.g. tubular, spherical and laminar-like particles) taken from the literature. $T_{\mathrm{p}}=$ crystallization peak temperature, $\mathrm{NE}=$ nucleating efficiency, $T_{10}=$ degradation temperature for $10 \%$ weight loss, $\Delta T_{10}=$ thermal stability increment of $T_{10}$ compared to value for neat iPP

\begin{tabular}{|c|c|c|c|c|c|}
\hline Nanocomposites & $\begin{array}{l}\text { Nanofiller } \\
\text { content }(w t \%)\end{array}$ & $\begin{array}{l}T_{\mathrm{p}} \\
\left({ }^{\circ} \mathrm{C}\right)\end{array}$ & $\begin{array}{l}\mathrm{NE} \\
(\%)\end{array}$ & $\begin{array}{l}T_{10} \\
\left({ }^{\circ} \mathrm{C}\right)\end{array}$ & $\begin{array}{l}\Delta T_{10} \\
\left({ }^{\circ} \mathrm{C}\right)\end{array}$ \\
\hline \multirow[t]{4}{*}{ PP/INT- $\mathrm{MoS}_{2}$} & 0 & 107.1 & 0 & 383 & 0 \\
\hline & 0.1 & 111 & 12 & 437 & 54 \\
\hline & 0.5 & 117.1 & 30 & 442 & 59 \\
\hline & 1 & 117.2 & 31 & 442 & 59 \\
\hline \multirow[t]{6}{*}{$\mathrm{PP} / \mathrm{HNTs}^{28,32}$} & 0 & 116.1 & 0 & 400 & 0 \\
\hline & 1 & 120 & 16 & - & - \\
\hline & 5 & 125 & 37 & - & - \\
\hline & 10 & 126.1 & 42 & 460 & 60 \\
\hline & 20 & 128.9 & 54 & - & - \\
\hline & 30 & 129.9 & 58 & 446 & 46 \\
\hline \multirow[t]{6}{*}{ PP/CNTs (MWNTs) ${ }^{31,34}$} & 0 & 112 & 0 & 356 & 0 \\
\hline & 0.1 & 119.6 & 27 & - & - \\
\hline & 0.25 & 120.4 & 30 & - & - \\
\hline & 0.5 & 122.7 & 38 & - & - \\
\hline & 1 & 122 & 36 & - & - \\
\hline & 2 & - & - & 406 & 50 \\
\hline \multirow{3}{*}{$\mathrm{PP} /$ rod-Si $\mathrm{Si}_{3} \mathrm{~N}_{4}{ }^{30}$} & 0 & 110 & 0 & - & - \\
\hline & 1 & 112 & 7 & - & - \\
\hline & 2 & 113 & 10 & - & - \\
\hline \multirow[t]{2}{*}{ PP/Nanoclay (MMT) $29,38,39$} & 0 & 110 & 0 & - & 0 \\
\hline & 3 & 115 & 17.8 & - & 90 \\
\hline \multirow{6}{*}{ PP/IF-WS ${ }_{2}{ }^{11}$} & 0 & 108.2 & 0 & 395 & 0 \\
\hline & 0.1 & 118 & 31 & 406 & 11 \\
\hline & 1 & 121.2 & 41 & 409 & 14 \\
\hline & 2 & 127.2 & 60 & 410 & 15 \\
\hline & 4 & 128.7 & 65 & 422 & 27 \\
\hline & 8 & 130.3 & 70 & 439 & 44 \\
\hline
\end{tabular}

attributed to increased interfacial interactions between the nanoparticles and iPP that leads to an increase in the activation energy for degradation.

Layered silicates such as montmorillonite (MMT) also have similar effects on the thermal stability of the polymer matrix and in this case the degree of dispersion of the clay (intercalatedexfoliated) as well as the clay modifier employed can also have important effects on the thermal decomposition of polymers. ${ }^{36}$ Due to the characteristic layered structure in the polymer matrix and the nanoscopic dimensions of the filler particles, several effects have been observed that can explain the changes in the thermal properties, both improvement and acceleration. ${ }^{37}$ The level of surface activity may be directly influenced by the mechanical interfacial adhesion or thermal stability of the organic compound used to modify MMT. In particular, Sharma and Nayak $^{38}$ have reported that the formation of iPP nanocomposites depends on the type of surfactant, polarity of the surfactant, its nature (olefinic/nonolefinic) and processing conditions. In this study, two different surfactants were used with different intergallery spacing. $p$-Aminobenzoic acid showed higher mechanical and thermal properties because of the favourable interface between the nanoclay and the matrix, exhibiting higher $d$-spacing or swelling leading to a higher diffusion of polymeric chains into the galleries of silicate layers, and crystallite formation outside the silicate layer, a phenomenon that was pronounced in the case of $p$-aminobenzoic when compared to octadecylamine. With further addition of $20 \mathrm{wt} \%$ PP-g-MA to the nanocomposites the aggregates disappeared and the nanoclays were finely dispersed in the PP matrix forming an exfoliated system, which could be the reason for a dramatic improvement in thermal properties corresponding to $\sim 87^{\circ} \mathrm{C}$ in $T_{10}$. In another investigation Sharma et al. ${ }^{39}$ showed that clay reinforcement occurs at the nanolevel, and a fully exfoliated nanocomposite system was obtained with $3 \mathrm{wt} \% \mathrm{C} 20 \mathrm{~A}$ containing $20 \mathrm{wt} \%$ PP-g-MA that exhibited no difference in polarity between the maleic anhydride modified clay and the matrix. The dramatic improvement in thermal stability was related to the confinement of the single nanoparticles in approximately $1 \mathrm{~nm}^{3}$ volume showing the existence of a single nanoparticle effect. Another reason for the excellent performance could be attributed to the formation of carbonaceous silicate char build up on the surface that insulates the underlying material and impedes the escape of volatile products generated during the decomposition. The above postulates for the increase in the thermal stability of around $90{ }^{\circ} \mathrm{C}$ explained the formation of exfoliated structure in the presence of PP-g-MA (Table 1).

It is reasonable to propose that the barrier effects of INT- $\mathrm{MoS}_{2}$ with tubular structure may somewhat be inferior to those of the aforementioned layered silicate nanofillers. However, the thermal stability of the iPP/INT-MoS $2(1 \mathrm{wt} \%)$ nanocomposites reported here is certainly not inferior to the literature data for the iPP/layered silicate nanocomposites. ${ }^{4}$ Therefore it may be concluded that the barrier effects of INT- $\mathrm{MoS}_{2}$ are not the primary factor in determining the thermal stability of $\mathrm{iPP} / \mathrm{INT}-\mathrm{MoS}_{2}$ nanocomposites. The thermal stability of the individual components and the nature of the interface of the composites are also crucial factors to obtain nanocomposites with enhanced thermal properties. On the other hand, it is important to point out that the improvements in $T_{10}$ values of $\mathrm{iPP} / \mathrm{INT}-\mathrm{MoS}_{2}$ nanocomposites are higher than those achieved in iPP/IF-WS $\mathrm{W}_{2}$, suggesting that the INT-MoS $\mathrm{S}_{2}$ reinforcements are more effective in enhancing the thermal stability of iPP than quasi-spherical IF-WS ${ }_{2} \cdot{ }^{11}$

\subsection{Mechanical properties}

The mechanical properties of iPP, especially the modulus, can be effectively improved using INT-MoS 2 . Fig. 2 shows typical tensile tests of $\mathrm{iPP} / \mathrm{INT}-\mathrm{MoS}_{2}$ nanocomposites, and the average data of Young's modulus $(E)$, tensile strength $\left(\sigma_{\mathrm{y}}\right)$, strain at yield $\left(\varepsilon_{\mathrm{y}}\right)$, strength at break $\left(\sigma_{\mathrm{b}}\right)$ and strain at break $\left(\varepsilon_{\mathrm{b}}\right)$ are collected in Table 2. It can be observed that the addition of INT-MoS progressively enhances the Young's modulus of the matrix, with increments of 15,28 and $40 \%$ for loading fractions of $0.1,0.5$, $1 \mathrm{wt} \%$, respectively, showing a non-linear growth of the modulus with the filler content, the increase being more pronounced at low loadings. This can be more clearly observed in Fig. 3, which presents the variation of Young's modulus as a function of the INT- $\mathrm{MoS}_{2}$ content. The improved $E$ obtained in this work is ascribed to the very uniform dispersion of the INT-MoS 2 and its high aspect ratio, which results in a larger nanofiller-polymer interfacial area. Qualitatively similar trends were found for the tensile strength, where the increments were around 13, 34 and $41 \%$ for the abovementioned nanofiller contents. On the other hand, the incorporation of the inorganic nanotubes leads to a slight decrease in both $\varepsilon_{\mathrm{y}}$ and $\varepsilon_{\mathrm{b}}$. The decrease is considerably more significant for the highest loading tested where the 


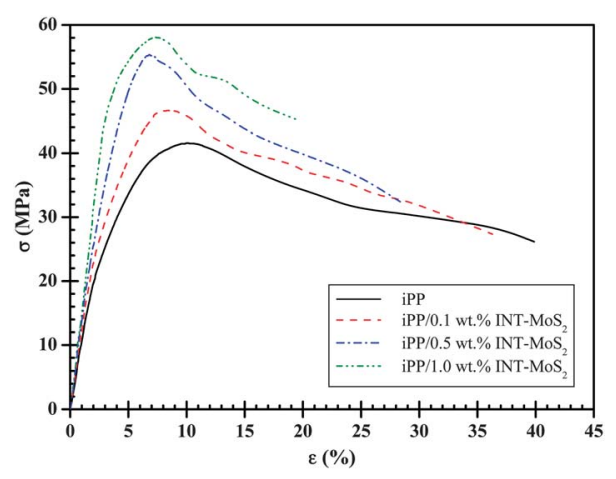

Fig. 2 Tensile properties of iPP versus INT- $\mathrm{MoS}_{2}$ content: (a) representative stress-strain curves, (b) Young's modulus, (c) tensile strength and (d) strain at break.

reduction in $\varepsilon_{\mathrm{b}}$ was about $52 \%$. This is a typical behaviour of nanofiller-reinforced polymer composites, since the nanofillers restrict the ductile flow of the matrix, and is in agreement with the results reported by Lopez-Gaxiola et $a l^{40}$ for carbon filler reinforced PP composites.

The area under the tensile curve is a measure of the toughness of the system. In these nanocomposites the area increased slightly for very low nanofiller contents and then decreased progressively, the reduction being $\sim 28 \%$ for the sample loaded with $1 \mathrm{wt}^{\%} \%$ INT-MoS ${ }_{2}$. This reduction is related to the aforementioned decrease in the ductility of the matrix, and indicates that the addition of high INT- $\mathrm{MoS}_{2}$ contents reduces the ability of the material to absorb energy during the deformation process.

Many models can be used to predict the tensile modulus of a two-component composite material. One of the most basic approaches is the Krenchel's rule of mixtures for discontinuous reinforcement: ${ }^{41}$

$$
E_{\mathrm{c}}=\left(\eta E_{\mathrm{f}}-E_{\mathrm{m}}\right) V_{\mathrm{f}}+E_{\mathrm{m}}
$$

where $E_{\mathrm{f}}$ and $E_{\mathrm{m}}$ are the tensile modulus of the filler and matrix, respectively, $V_{\mathrm{f}}$ is the filler volume fraction and $\eta$ is the strengthening efficiency coefficient, which is assumed to be $1 / 5$ for randomly oriented fillers. Taking $E_{\mathrm{f}}$ as $240 \mathrm{GPa},{ }^{42}$ the values of $E_{\mathrm{c}}$ for the composites were calculated, and the results are plotted in Fig. 3 (solid line). As can be observed, the experimental results are systematically higher than the theoretical predictions, with differences in the range of $10-13 \%$ probably due to the fact that the model underestimates the effect of these nanofillers with a very high aspect ratio. A more accurate prediction can be obtained by the Halpin-Tsai equation, ${ }^{43}$ which enables to express the modulus of the composite in terms of the modulus of the matrix and the reinforcing elements considering their proportions and geometry, and for randomly oriented fillers can be written as:

$$
\begin{aligned}
E_{\mathrm{c}} & =\left[\frac{3}{8}\left(\frac{1+2 s \eta_{\mathrm{L}} V_{\mathrm{f}}}{1-\eta_{L} V_{f}}\right)+\frac{5}{8}\left(\frac{1+2 \eta_{\mathrm{T}} V_{\mathrm{f}}}{1-\eta_{\mathrm{T}} V_{\mathrm{f}}}\right)\right] E_{\mathrm{m}} \\
\eta_{\mathrm{L}} & =\frac{\left(E_{\mathrm{f}} / E_{\mathrm{m}}\right)-1}{\left(E_{\mathrm{f}} / E_{\mathrm{m}}\right)+2 s} \\
\eta_{\mathrm{T}} & =\frac{\left(E_{\mathrm{f}} / E_{\mathrm{m}}\right)-1}{\left(E_{\mathrm{f}} / E_{\mathrm{m}}\right)+2}
\end{aligned}
$$

where $s$ is the aspect ratio of the reinforcement, and the rest of the parameters were described previously. Assuming an average aspect ratio of 2500 for the INT- $\mathrm{MoS}_{2},{ }^{15}$ the values predicted by this model were estimated, and are also plotted in Fig. 3 (dashed lines). The results obtained from eqn (3) are in better agreement with the experimental data, with differences $<9 \%$. Higher deviations were obtained from the Lewis and Nielsen mode ${ }^{44}$ (data not shown), which takes into account the aspect ratio, orientation and packing of the fillers. New models could be developed to predict more accurately the modulus of nanofiller reinforced composites at very low volume fractions.

To further assess the reinforcing efficiency of INT-MoS 2 , the flexural properties of the INT-MoS $\mathrm{S}_{2}$ filled iPP nanocomposites were also investigated (Table 3). It appears that addition of $\mathrm{MoS}_{2}$ inorganic nanotubes leads to an improvement in the flexural modulus and strength of iPP. The addition of increasing contents of INT- $\mathrm{MoS}_{2}$ causes a gradual enhancement in the flexural modulus (Fig. 4), following similar trends to those described for the Young's modulus, and with increments in the range of 13$29 \%$ for the loading fractions studied, slightly lower than those attained for the Young's modulus. Significant enhancements were also observed for the flexural strength, which increased by about $23 \%$ at $1 \mathrm{wt}^{\mathrm{t}} \%$ loading. All these results corroborate the good dispersion of the INT- $\mathrm{MoS}_{2}$ within the iPP matrix.

The study of the effect of INT-MoS ${ }_{2}$ loading on the Charpy notched impact strength of $\mathrm{iPP} / \mathrm{INT}-\mathrm{MoS}_{2}$ nanocomposites was carried out at room temperature to obtain more information about the toughness of the nanocomposites, and the results are also collected in Table 3. The incorporation of 0.1 and $0.5 \mathrm{wt} \%$ INT- $\mathrm{MoS}_{2}$ increases the impact strength of $\operatorname{iPP}\left(\sim 3.5 \mathrm{~kJ} \mathrm{~m}^{-2}\right)$ by 16 and $9 \%$, respectively, whilst higher loadings lead to a slight decrease in toughness (i.e. $\sim 8 \%$ at $1 \mathrm{wt} \%$ content) (Fig. 5). This dependence of the impact strength on the nanofiller content is in agreement with the analysis of the areas under the tensile curves.

\begin{tabular}{|c|c|c|c|c|c|c|}
\hline INT-MoS ${ }_{2}$ content $(w t \%)$ & \multicolumn{6}{|l|}{ Tensile tests } \\
\hline 0.1 & $1.46 \pm 0.06$ & $46.7 \pm 2$ & $8.3 \pm 0.2$ & $27.2 \pm 1$ & $36.4 \pm 0.5$ & $1285 \pm 35$ \\
\hline 0.5 & $1.63 \pm 0.08$ & $55.2 \pm 2$ & $6.7 \pm 0.3$ & $28.4 \pm 1$ & $32.8 \pm 0.6$ & $1180 \pm 46$ \\
\hline 1 & $1.78 \pm 0.05$ & $57.9 \pm 1$ & $7.4 \pm 0.1$ & $45.5 \pm 2$ & $19.3 \pm 0.5$ & $914 \pm 58$ \\
\hline
\end{tabular}
The toughness of these nanocomposites improved noticeably at

Table 2 Mechanical parameters derived from the room temperature tensile tests of iPP/INT-MoS ${ }_{2}$ nanocomposites. $E$ : Young's modulus, $\sigma_{\mathrm{y}}$ : tensile strength at yield, $\varepsilon_{\mathrm{y}}$ : strain at yield, $\sigma_{\mathrm{b}}$ : tensile strength at break, $\varepsilon_{\mathrm{b}}$ : strain at break, $A$ : area under the curve 


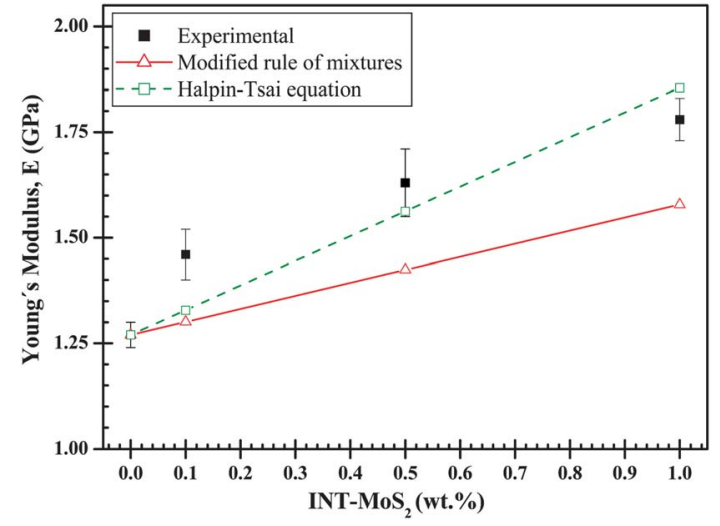

Fig. 3 Experimental and theoretical predictions of the Young's modulus $(E)$ as a function of the INT-MoS 2 content.

Table 3 Mechanical parameters derived from the flexural and Charpy impact tests of iPP/MoS $/ \mathrm{S}_{2}$ nanocomposites. $E_{\mathrm{f}}$ : flexural modulus, $\sigma_{\mathrm{fm}}$ : flexural strength, $F$ : impact force and $E_{\text {charpy }}$ : impact strength

\begin{tabular}{llllll}
\hline & \multicolumn{2}{l}{ Flexural tests } & & \multicolumn{2}{l}{ Charpy impact tests } \\
\cline { 2 - 3 } \cline { 5 - 6 } $\begin{array}{lllll}\text { INT-MoS } \\
\text { content }(w t \%)\end{array}$ & $E_{\mathrm{f}}(\mathrm{GPa})$ & $\sigma_{\mathrm{fm}}(\mathrm{MPa})$ & & $F(\mathrm{~N})$ & $E_{\text {charpy }}\left(\mathrm{kJ} \mathrm{m}^{-2}\right)$ \\
\hline 0 & $1.68 \pm 0.12$ & $53.9 \pm 2$ & & $430 \pm 20$ & $3.48 \pm 0.22$ \\
0.1 & $1.90 \pm 0.11$ & $59.8 \pm 2$ & & $550 \pm 30$ & $4.02 \pm 0.28$ \\
0.5 & $2.09 \pm 0.16$ & $64.6 \pm 3$ & & $470 \pm 50$ & $3.81 \pm 0.19$ \\
1 & $2.17 \pm 0.14$ & $66.2 \pm 2$ & & $410 \pm 20$ & $3.24 \pm 0.25$ \\
\hline
\end{tabular}

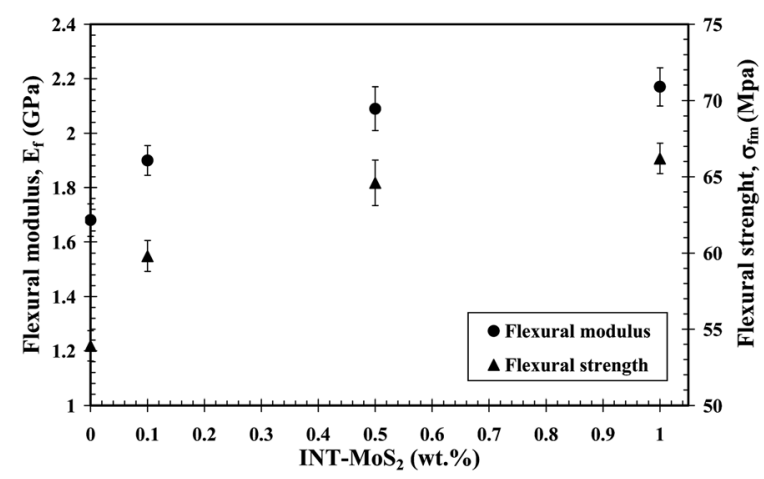

Fig. 4 Flexural properties of iPP versus INT-MoS ${ }_{2}$ content.

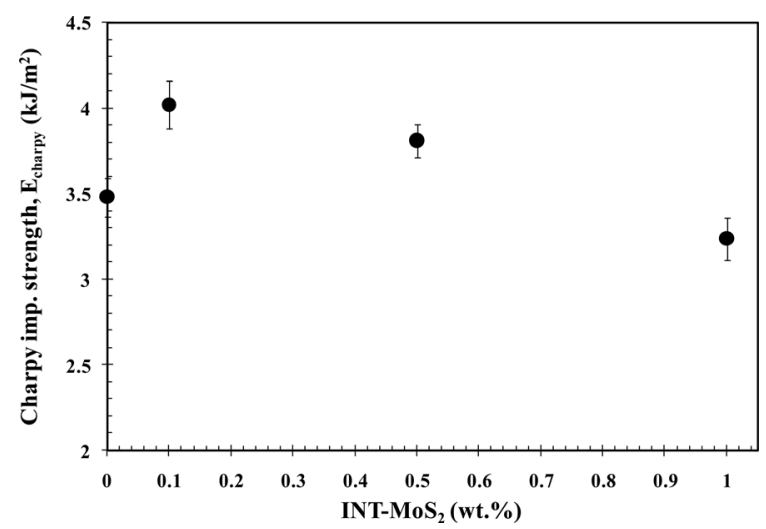

Fig. 5 Charpy impact strength $\left(E_{\text {charpy }}\right)$ of iPP versus INT-MoS content. very low INT-MoS 2 contents, probably due to the better dispersion and distribution of INT-MoS 2 in the iPP matrix. In addition, the large aspect ratio of the inorganic nanotubes can lead to a complex matrix-filler interaction during nanotube bridging, breaking and pullout, which is likely to promote the local plastic deformation of the matrix.

It is also interesting to compare the reinforcement of INT$\mathrm{MoS}_{2}$ with other nanofillers with different morphologies, including HNTs, CNTs, silicon nitride $\left(\mathrm{Si}_{3} \mathrm{~N}_{4}\right)$ rods, layered silicates (MMT), and IF-WS ${ }_{2}$ that have been melt-compounded with PP. Table 4 shows the percentage variations in the mechanical properties of iPP nanocomposites containing similar amounts $(\sim 1 \mathrm{wt} \%)$ of these nanofillers. It is well-known that the reinforcing effects of any filler type on the mechanical properties of polymer composites depend strongly on shape, particle size, aggregate size, aspect ratio, surface characteristics and degree of dispersion, which are often interrelated, making it difficult to vary one feature independently of the other. In the present work remarkable improvements in the mechanical properties are observed for $\mathrm{iPP} / \mathrm{INT}-\mathrm{MoS}_{2}$ where non-modified INT-MoS ${ }_{2}$ is dispersed uniformly in the iPP matrix at all compositions prepared. ${ }^{15}$ The order of magnitude of increase in the moduli and strength is globally similar to those obtained for inorganic fullerene-like $\mathrm{WS}_{2}$ nanoparticles, ${ }^{45}$ and far exceeds the performance of both modified HNTs ${ }^{46}$ and MWCNTs. ${ }^{44}$ However, silicon nitrides clearly provide the best reinforcement for the PP matrix, which has been related to the alignment and exfoliation of rod-shaped $\mathrm{Si}_{3} \mathrm{~N}_{4}$ particles. ${ }^{30}$ These phenomena were also mainly responsible for the $95 \%$ enhancement in tensile strength and $152 \%$ increase in tensile modulus of PP using $p$-aminobenzoic acid modified clay with PP-g-MA compatibilizer. ${ }^{38}$ On the other hand, Table 4 also compares the impact resistance of PP matrices incorporating different nanofillers. In particular, the data indicate that the use of quaternary ammonium salt modified halloysites (QM-HNTs) led to globally improved performances which have been ascribed to synergistic effects of the surface modification and dispersion of these inorganic nanotubes on a nano-scale in the PP matrix. ${ }^{46}$ Consequently, improved compatibility between iPP and INT-MoS 2 is an important milestone to obtain nanocomposites with a high level of dispersion that provides both high strength and ductility to the iPP nanocomposites.

Table 4 Percentage variations of mechanical properties of PP nanocomposites containing some amounts of nanofillers ( $1 \mathrm{wt} \%$ ) compared with the neat PP matrix

\begin{tabular}{|c|c|c|c|c|}
\hline \multirow[b]{2}{*}{ Nanocomposites } & \multicolumn{2}{|c|}{ Tensile tests } & \multicolumn{2}{|c|}{ Charpy impact tests } \\
\hline & $\begin{array}{l}\Delta E \\
(\mathrm{GPa})\end{array}$ & $\begin{array}{l}\Delta \sigma_{\mathrm{y}} \\
(\mathrm{MPa})\end{array}$ & $\begin{array}{l}\Delta \varepsilon_{\mathrm{b}} \\
(\%)\end{array}$ & $\begin{array}{l}\Delta E_{\text {Charpy }} \\
\left(\mathrm{kJ} \mathrm{m}^{-2}\right)\end{array}$ \\
\hline PP/INT-MoS ${ }_{2}$ & $40 \%$ & $41 \%$ & $-52 \%$ & $-8 \%$ \\
\hline $\mathrm{PP} / \mathrm{HNTs}^{a, 46^{2}}$ & $32 \%$ & $22 \%$ & $-15 \%$ & $37 \%$ \\
\hline $\begin{array}{l}\text { PP/CNTs } \\
\text { (MWNTs) }^{44}\end{array}$ & $23 \%$ & $15 \%$ & $-30 \%$ & $28 \%$ \\
\hline $\mathrm{PP} /$ rod-Si $_{3} \mathrm{~N}_{4}{ }^{30}$ & $722 \%$ & $292 \%$ & - & - \\
\hline $\begin{array}{l}\text { PP/Nanoclay } \\
\text { (MMT) }^{38}\end{array}$ & $152 \%$ & $95 \%$ & $0 \%$ & - \\
\hline $\mathrm{PP} / \mathrm{IF}-\mathrm{WS}_{2} 45$ & $39 \%$ & $41 \%$ & $-59 \%$ & $-19 \%$ \\
\hline
\end{tabular}

${ }^{a}$ Filler content is $2 \mathrm{wt}^{0} \%{ }^{b}$ Filler content is $3 \mathrm{wt} \%$. 


\subsection{Tribological properties}

Fig. 6a shows typical curves of the friction coefficient $(\mu)$ for neat iPP and the nanocomposites as a function of the sliding distance. It can be observed that the value of $\mu$ for iPP increases
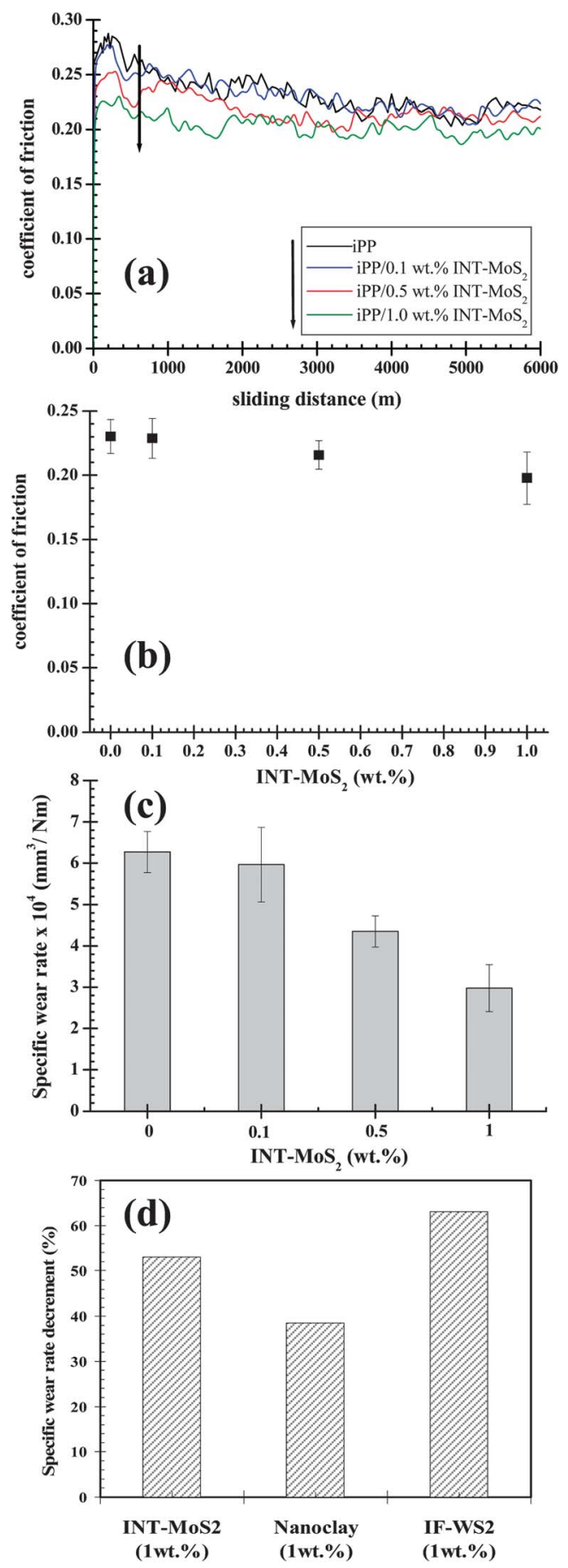

Fig. 6 Tribological properties of iPP/INT-MoS 2 nanocomposites. (a) Coefficient of friction as a function of the sliding distance. (b) Steady state coefficient of friction as a function of the INT- $\mathrm{MoS}_{2}$ content. (c) Specific wear rate of neat iPP and the nanocomposites and (d) percentage variations of specific wear rate of PP nanocomposites containing $1 \mathrm{wt} \%$ of nanofillers (e.g. INT- $\mathrm{MoS}_{2}$ [this work], nanoclay ${ }^{51}$ and IF- $-\mathrm{WS}_{2}{ }^{45}$ ) compared with the neat PP matrix. considerably during the early stages of the tribological test, ascribed to a progressive increase in temperature. After a certain sliding distance, the friction force and temperature reach a maximum at which point the shear strength and elastic modulus of the softer material decrease, making sliding between the polymer and the steel surfaces easier, hence the friction coefficient decreases, tending to a steady state.$^{47} \mathrm{~A}$ similar behaviour is found for nanocomposites with very low INT- $\mathrm{MoS}_{2}$ loadings, however, for the sample with $1 \mathrm{wt} \%$ nanotube content the initial increase is considerably less pronounced, indicating less softening of the matrix due to the presence of the nanofiller. Fig. $6 \mathrm{~b}$ shows the mean friction coefficient as a function of the INT$\mathrm{MoS}_{2}$ content. The addition of small amounts of this nanofiller leads to a progressive decrease in $\mu$, to about $15 \%$ at $1 \mathrm{wt} \%$ loading. This behaviour can be explained in terms of the lubricating effect of the INT- $\mathrm{MoS}_{2}$ and a very efficient dispersion of the nanotubes within the matrix. The shearing force decreased due to the lower shear strength of the lubricant nanofiller that results in a lower $\mu$. Moreover, the load bearing capacity and thermal resistance are improved by adding hard nanofillers, which increase the heat conductivity and lead to a reduction in the temperature during sliding contact. Fig. 6c compares the wear rate of iPP and the nanocomposites. With the incorporation of INT- $\mathrm{MoS}_{2}$ the wear resistance of the polymer is considerably enhanced and the nanocomposite with $1 \mathrm{wt} \%$ loading shows a reduction of about $53 \%$. These inorganic nanotubes dispersed in the polymer matrix can act both as a barrier and prevent largescale fragmentation of the iPP matrix. It was reported that nanofillers of similar dimensions as the segments of the surrounding polymer chains allow material removal to be milder and aid the formation of uniform tenacious transfer film. ${ }^{\mathbf{4 8 , 4 9}}$

The hardness contribution also plays a vital role in wear property improvement. ${ }^{50}$ Fig. $6 \mathrm{~d}$ also compares the percentage variations in the wear rate of PP nanocomposites containing $1 \mathrm{wt}$ $\%$ of nanoclay ${ }^{51}$ and IF-WS ${ }_{2}{ }^{45}$ In particular, PP/INT- $\mathrm{MoS}_{2}$ showed better wear property improvement than PP/nanoclays without the need for an exfoliation process. The effects of the CNT content on the wear properties and mechanical properties were mainly investigated by Lim et $a .^{52}$ who found that the CNTs played an important role in bridging molecular chainCNTs in the PP matrix, resulting in improvements in the wear and mechanical properties of the PP/CNT composites. However, the authors concluded that there was no clear, monotonic trend of decreasing friction coefficients with increased percentage of CNTs. The friction mechanism is complex and there are probably competing factors associated with it. The higher percentage improvement of wear rate is noticed for IF-WS 2 solid lubricant nanoparticles which have recently been identified as strong candidates for tribological applications in polymer nanocomposites like epoxy, ${ }^{53}$ nylon-6 (ref. 14) and poly(ether ether ketone). ${ }^{13,54}$ From the above data we can also suggest INT-MoS as promising tribological additives for thermoplastic polymers.

Considering the lubricating character of the INT-MoS , it is interesting to analyze the influence of these nanofillers on the surface energy of iPP. The total surface energy and its polar and dispersion components for neat iPP and the nanocomposites were calculated using eqn (1) and the results are shown in Fig. 7. The surface energy of neat iPP is about $32 \mathrm{mN} \mathrm{m}^{-1}$, and it decreases gradually with the addition of INT- $\mathrm{MoS}_{2}$, the 


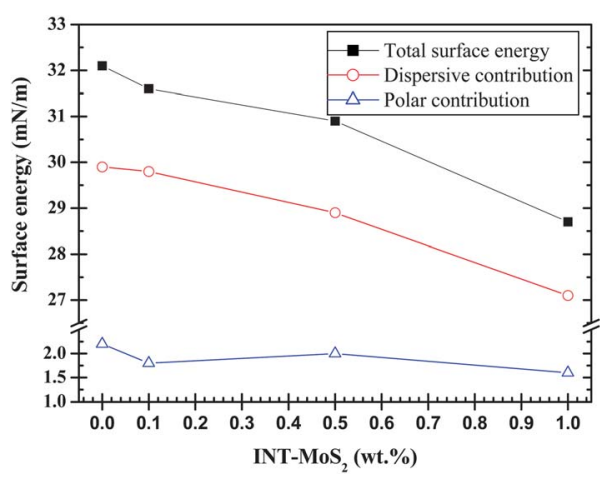

Fig. 7 Surface energy of iPP nanocomposites as a function of the INT-MoS 2 content.

reduction being around $11 \%$ for $1 \mathrm{wt} \%$ loading. A similar decrease was observed for the dispersive contribution, whereas the polar contribution remained approximately unchanged by the addition of these nanofillers. The observed decrease in the surface energy can be directly related to the lubricating character of the INT- $\mathrm{MoS}_{2}$ and the consequent improvement in tribological properties.

\section{Conclusion}

In the present investigation, the incorporation of well-dispersed INT-MoS 2 into the iPP matrix provides an alternative strategy for overcoming the limitations of polymer nanocomposites (i.e. performance, cost effectiveness and processability), and offers new prospects in the preparation of advanced materials. The INT- $\mathrm{MoS}_{2}$ shows promise for improving both the thermal stability and the crystallization rate of iPP when compared with other nanosized particles such as HNTs, CNTs, silicon nitrides, nanoclays and inorganic fullerenes. The thermal stability reflected by the temperature at $10 \%$ weight loss in nitrogen of nanocomposites filled with $1 \mathrm{wt} \%$ of INT-MoS 2 was almost $60{ }^{\circ} \mathrm{C}$ higher than that of neat iPP. The INT-MoS filler also serves as an effective nucleating agent facilitating the crystallization of iPP. Significant enhancement in tensile and flexural properties of the iPP matrix has been observed with addition of $1 \mathrm{wt} \%$ of INT$\mathrm{MoS}_{2}$, and the order of magnitude of the increase in moduli and strength is globally similar to that obtained with IF-WS $\mathrm{Wano}_{2}$ particles, far exceeding both modified HNTs and CNTs (1 wt $\%$ ). Silicon nitrides clearly provided the best reinforcement for the PP matrix, which has been related to the alignment and exfoliation of rod-shaped $\mathrm{Si}_{3} \mathrm{~N}_{4}$ particles, a phenomenon also mainly responsible for the remarkable enhancement in tensile strength and modulus of PP using combined modifier/compatibilizer systems. In addition, the impact resistance of iPP nanocomposites reaches a maximum with addition of the modified HNTs that has been ascribed to synergistic effects of surface modification and dispersion of inorganic nanotubes on a nanoscale in the PP matrix. Consequently, improved compatibility between iPP and INT-MoS 2 will be a crucial factor to obtain nanocomposites with a high level of dispersion in order to provide both high strength and ductility to the iPP nanocomposites. The investigation of the tribological behaviour reveals that the nanocomposites exhibit markedly improved wear properties with the addition of INT-MoS 2 . Based on the thermal, mechanical and tribological data, it can be concluded that these environmentally friendly inorganic $\mathrm{MoS}_{2}$ nanotubes have promising prospects for the development of new polymer nanocomposites for structural and functional applications.

\section{Acknowledgements}

Dr M. Naffakh would like to acknowledge the Ministerio de Economía y Competitividad (MINECO) for a 'Ramón y Cajal' Research Fellowship and Dr Ana Diez-Pascual wishes to acknowledge the CSIC for a JAE Postdoctoral Fellowship. This work was supported by the Spanish Ministry of Science \& Innovation in the Project MAT-2010-21070-C02-01. Dr Maja Remskar would like to thank Mr Janez Jelenc for technical help in the synthesis of the $\mathrm{MoS}_{2}$ nanotubes and the Slovenian Research Agency of the Republic of Slovenia for financial support, contracts no. J2-2115 and J1-2352.

\section{References}

1 E. P. Giannelis, Adv. Mater., 1996, 8, 29.

2 M. Moniruzzaman and K. I. Winey, Macromolecules, 2006, 39, 5194.

3 K. L. Winey and R. A. Vaia, MRS Bull., 2007, 32, 314.

4 S. Pavlidou and C. D. Papaspyrides, Prog. Polym. Sci., 2008, 33, 1119.

5 W. Caseri, Chem. Eng. Commun., 2009, 196, 549.

6 H. Kim, A. A. Abdala and C. W. Macosko, Macromolecules, 2010, 43, 6515 .

7 R. Tenne, L. Margulis, M. Genut and G. Hodes, Nature, 1992, 360, 444.

8 L. Margulis, G. Salitra, R. Tenne and M. Talianker, Nature, 1993, $365,113$.

9 M. Remskar, Adv. Mater., 2004, 16, 1497.

10 R. Tenne, Nat. Nanotechnol., 2006, 1, 103.

11 M. Naffakh, Z. Martín, N. Fanegas, C. Marco, M. A. Gómez and I. Jiménez, J. Polym. Sci., Part B: Polym. Phys., 2007, 45, 2309.

12 M. Naffakh, C. Marco, M. A. Gómez and I. Jiménez, J. Phys. Chem. $B, 2009, \mathbf{1 1 3}, 7107$.

13 M. Naffakh, A. M. Díez-Pascual, C. Marco, M. A. Gómez and I. Jiménez, J. Phys. Chem. B, 2010, 114, 11444.

14 M. Naffakh, C. Marco, M. A. Gómez and I. Jiménez, Mater. Chem. Phys., 2011, 129, 641.

15 M. Naffakh, M. Remškar, C. Marco, M. A. Gómez and I. Jiménez, J. Mater. Chem., 2011, 21, 3574.

16 M. Naffakh, C. Marco and M. A. Gómez, J. Phys. Chem. B, 2011, 115, 2248.

17 M. Naffakh, M. Remškar, C. Marco and M. A. Gómez, J. Phys. Chem. B, 2011, 115, 2850.

18 A. Zak, L. Sallacan-Ecker, A. Margolin, M. Genut and R. Tenne, Nano, 2009, 4, 91.

19 E. Zohar, S. Baruch, M. Shneider, H. Dodiuk, S. Kenig, R. Tenne and H. D. Wagner, J. Adhes. Sci. Technol., 2011, 25, 1603.

20 C. S. Reddy, A. Zak and E. Zussman, J. Mater. Chem., 2011, 21, 16086.

21 M. Remskar, A. Mrzel, M. Virsek and A. Jesih, Adv. Mater., 2007, 19, 4276.

22 M. Remskar, M. Virsek and A. Mrzel, Appl. Phys. Lett., 2009, 95, $133-122$.

23 J. Jelenc and M. Remskar, Nanoscale Res. Lett., 2012, 7, 208.

24 D. K. Owens and R. C. Wendt, J. Appl. Polym. Sci., 1969, 13, 1741.

25 B. Fillon, B. Lotz, A. Thierry and J. C. Wittmann, J. Polym. Sci., Part B: Polym. Phys., 1993, 31, 1395.

26 B. Fillon, A. Thierry, B. Lotz and J. C. Wittmann, J. Therm. Anal., 1994, 42, 721.

27 C. Marco, M. A. Gómez, G. Ellis and J. M. Arribas, J. Appl. Polym. Sci., 2002, 84, 1669.

28 M. Liu, B. Guo, M. Du, F. Chen and D. Jia, Polymer, 2009, 50, 3022. 
29 W. Xu, M. Ge and P. He, J. Polym. Sci., Part B: Polym. Phys., 2002, 40, 408.

30 V. K. Rangari, Y. M. Shaik, G. M. Mohammad and S. Jeelani, J. Appl. Polym. Sci., 2011, 121, 1512.

31 C. Marco, M. Naffakh, M. A. Gómez, G. Santoro and G. Ellis, Polym. Compos., 2011, 42, 935.

32 M. Du, B. Guo and D. Jia, Eur. Polym. J., 2006, 42, 1362.

33 R. Kotsilkova, E. Ivanov, E. Krusteva, C. Silvestre, S. Cimmino and D. Duraccio, J. Appl. Polym. Sci., 2010, 115, 3576.

34 S. H. Jin, C. H. Kang, K. H. Yoon, D. S. Bang and Y. B. Park, Appl. Polym. Sci., 2009, 111, 1028.

35 B. B. Marosfói, A. Szabó, G. Marosi, D. Tabuani, G. Camino and S. Pagliari, J. Therm. Anal. Calorim., 2006, 86, 669.

36 K. Chrissafisa and D. Bikiaris, Thermochim. Acta, 2011, 523, 1.

37 A. Leszczynska, J. Njuguna, K. Pielichowski and J. R. Banerjee, Thermochim. Acta, 2007, 453, 75.

38 S. K. Sharma and S. K. Nayak, Polym. Degrad. Stab., 2009, 94, 132.

39 S. K. Sharma, A. K. Nema and S. K. Nayak, J. Appl. Polym. Sci., $2010,115,3463$.

40 D. L. Lopez-Gaxiola, M. M. Jubinski, J. M. Keith, J. A. King and I. Miskioglu, J. Appl. Polym. Sci., 2010, 118, 1620.
41 H. Krenchel, Fibre Reinforcement, Akademisk Forlag, Copenhagen, 1964, p. 159

42 T. Lorenz, D. Teich, J. O. Joswing and G. Seifert, J. Phys. Chem. C, 2012, 116, 11714.

43 J. C. Halpin and L. C. Kardos, Polym. Eng. Sci., 1976, 16, 344.

44 T. Lewis and L. Nielsen, J. Appl. Polym. Sci., 1970, 14, 1449.

45 M. Naffakh, A. M. Díez-Pascual, C. Marco and G. Ellis, in preparation.

46 K. Prashantha, M. F. Lacrampe and P. Krawczak, eXPRESS Polym. Lett., 2011, 5, 295.

47 N. E. Bekhet, Wear, 1999, 236, 55.

48 Q. H. Wang, J. Xu, W. Shen and Q. Xue, Wear, 1997, 209, 316.

49 C. J. Shwartz and S. Bahadur, Wear, 2000, 237, 261.

50 J. Khedkar, L. Negulescu and E. I. Meletis, Wear, 2002, 252, 361.

51 K. Kanny, P. Jawahar and V. K. Moodley, J. Mater. Sci., 2008, 43, 7230.

52 Y. Lui and J. Gao, Adv. Mater. Res., 2011, 299-300, 798.

53 L. Rapoport, O. Nepomnyashchy, A. Verdyan, R. Popovitz-Biro, Y. Volovik, B. Ittah and R. Tenne, Adv. Eng. Mater., 2004, 6, 44.

54 X. Hou, C. X. Shan and K. L. Choy, Surf. Coat. Technol., 2008, 202, 2287. 